\title{
ANALISIS KORESPONDENSI UNTUK MELIHAT POLA HUBUNGAN FAKTOR - FAKTOR ALASAN MAHASISWA TERHADAP PEMILIHAN JURUSAN MATEMATIKA DI FMIPA UNTAD
}

\author{
N. Rahmayani ${ }^{1}$, Rais ${ }^{2}$, I.T. Utami ${ }^{3}$ \\ 1,2,3 Program Studi Matematika Jurusan Matematika FMIPA Universitas Tadulako Jalan \\ Soekarno Hatta Km. 09 Tondo, Palu 94118, Indonesia \\ 1Yanirahma692@gmail.com,2rais76untad@yahoo.co.id, ${ }^{2}$ triutammi.iut@gmail.com
}

\begin{abstract}
The high number of departments organized by the college aims to accommodate the interests and talents of the students who will continue their education to a higher level. But many prospective students choose their major just by simply selecting which is important to study without considering the sequel, both in the lecture and after graduation. This research uses the method of correspondence analysis to look at the pattern of relationship factors of the reasonswhy the students of Mathematics Departments at the Faculty of Science of Tadulako University choose Mathematics as their major. Correspondence analysis studies the relationship between two or more qualitative variables using the graphically multivariate techniques used for data exploration of a contingency table. The results of chi square test shows that there are 3 variables, interest and talent factors, alumnus prospects, and job opportunities factor. Theresults of correspondence analysis only produces one dimension on each variable and generates value contributions. The pattern of the relationship between the major selection and interests and talents factor shows that most of the respondences are in the strongly agreed criteria (SS) which is worth $58.9 \%$. So do those of the relationships between major selection and alumnus prospect and those between major selection and job opportunities, their also shows that most of the respondences are in the strongly agreed criteria (SS), worth $53.9 \%$ and $64.2 \%$ respectively.
\end{abstract}

Keywords $\quad$ : Correspondence Analysis, Selection Factor Major, Major, Chy Square Test

\section{ABSTRAK}

Banyaknya jurusan yang diselenggarakan oleh Perguruan Tinggi bertujuan untuk menampung minat dan bakat dari calon mahasiswa yang akan melanjutkan pendidikan ke jenjang yang lebih tinggi. Akan tetapi tidak sedikit calon mahasiswa tersebut memilih jurusan kuliah hanya asal pilih yang penting bisa kuliah tanpa mempertimbangkan kelanjutannya, baik dalam masa perkuliahan maupun pasca kelulusan.Penelitian ini menggunakan metode analisis korespondensi untuk melihat pola hubungan faktor-faktor alasan mahasiswa dalam pemilihan jurusan matematika diFMIPA UNTAD. Analisis korespondensi adalah suatu ilmu yang mempelajari hubungan antara dua atau lebih peubah kualitatif, yaitu dengan teknik multivariat secara grafik yang digunakan untuk eksplorasi data dari sebuah tabel kontigensi. Dari hasil pengujian chi square diperoleh 3 variabel faktor yang memenuhi syarat $X^{2}>$ 9,488 yang masuk kedalam analisis korespondensi yaitu terdiri dari variabel faktor minat dan bakat, faktor prospek lulusan serta faktor lowongan kerja. Pada hasil analisis korespondensi 
hanya menghasilkan 1 dimensi pada masing-masing variabel dan menghasilkan nilai kontribusi. Pada pola hubungan antara pemilihan jurusan dengan faktor minat dan bakat mempunyai nilai kontribusi terbesar pada kriteria sangat setuju (SS) yang bernilai $58,9 \%$. Kemudian untuk pola hubungan antara pemilihan jurusan dengan prospek lulusan mempunyai nilai kontribusi terbesar pada kriteria sangat setuju (SS) yang bernilai $53,9 \%$. Sedangkan untuk pola hubungan antara pemilihan jurusan dengan lowongan kerja mempunyai nilai kontribusi terbesar pada kriteria sangat setuju (SS) yang bernilai $64,2 \%$.

Kata Kunci : Analisis Korespondensi, Faktor Pemilihan Jurusan, Jurusan, Uji Chi Square

\section{PENDAHULUAN}

\subsection{Latar Belakang}

Pemilihan jurusan oleh seorang calon mahasiswa bukanlah hal yang mudah dan dapat diremehkan, karena banyak hal yang harus dipertimbangkan seperti biaya, kemampuan diri, dan Perguruan Tinggi yang dituju. Banyaknya jurusan yang diselenggarakan oleh Perguruan Tinggi bertujuan untuk menampung minat dan bakat dari calon mahasiswa yang akan melanjutkan pendidikan ke jenjang yang lebih tinggi. Akan tetapi tidak sedikit calon mahasiswa tersebut memilih jurusan kuliah hanya asal pilih yang penting bisa kuliah tanpa mempertimbangkan kelanjutannya, baik dalam masa perkuliahan maupun pasca kelulusan. Hal ini menyebabkan rendahnya tingkat nilai yang dicapai oleh mahasiswa tersebut yang tentu saja menghambat kelulusan.

Pada dasarnya faktor-faktor yang dapat mempengaruhi alasan mahasiswa dalam pemilihan jurusan matematika sebagai tempat kuliah yaitu terdiri dari faktor biaya kuliah, faktor akreditas Jurusan, faktor beasiswa, faktor dorongan orang tua, faktor dorongan teman, faktor minat dan bakat, faktor prospek lulusan, serta faktor lowongan kerja. Sehingga setiap mahasiswa pasti telah mempertimbangkan beberapa faktor dalam pemilihan jurusan, salah satunya yang berhubungan dengan dunia kerja, tentunya peluang pekerjaan yang kelak akan didapatkan setelah selesai menjalankan program studi yang telah ditempuh.

Dalam penelitian ini akan menggunakan metode analisis korespondensi untuk melihat pola hubungan faktor-faktor alasan Mahasiswa dalam pemilihan Jurusan matematika diFMIPA UNTAD. Pada penelitian sebelumnya, Chofifatul Jannah telah melakukan penelitian tetang analaisis korespondensi untuk mengetahui alasan mahasiswa memilih jurusan di FMIPA Universitas Negeri Malang dengan studi kasus mahasiswa non kependidikan FMIPA Universitas Negeri Malang pada tahun 2011.

\subsection{Rumusan Masalah}

Berdasarkan latar belakang yang telah disampaikan sebelumnya, maka permasalahan yang akan diteliti adalah sebagai berikut : 
1. Apakah ada hubungan antara Jurusan Matematika di FMIPA UNTAD dan faktor alasan Mahasiswa dalam pemilihan Jurusan?

2. Bagaimana pola hubungan faktor-faktor alasan Mahasiswa dalam pemilihan Jurusan matematika di FMIPA UNTAD?

\subsection{Tujuan Penelitian}

Tujuan dari penelitian ini adalah :

1. Untuk mengetahui apakah ada hubungan antara Jurusan Matematika di FMIPA UNTAD dan faktor alasan Mahasiswa dalam pemilihan Jurusan

2. Untuk melihat pola hubungan faktor-faktor alasan Mahasiswa dalam pemilihan Jurusan matematika di FMIPA UNTAD

\subsection{Batasan Masalah}

Batasan masalah dalam penelitian ini adalah penulis tidak mengambil semua jurusan yang ada pada fakultas MIPA UNTAD melaikan hanya mengambil jurusan Matematika yang terdiri dari prodi Matematika dan prodi Statistik 2012-2015 saja.

\subsection{Manfaat Penelitian}

Manfaat yang ingin diperoleh dalam penelitian ini adalah memberi masukan bagi mahasiswa untuk menambah pengetahuan tentang analisis korespondensi dalam ilmu statistik, serta wawasan bagi penulis tentang hubungan antara Jurusan Matematika di FMIPA UNTAD dan faktor alasan Mahasiswa dalam pemilihan Jurusan.

\section{METODE PENELITIAN}

\subsection{Jenis Data dan Variabel Penelitian}

Jenis data yang digunakan dalam penelitian ini berupa data kualitatif, berasal dari data kuesioner yang diteransformasikan menjadi data kuantitatif. Dalam penelitian ini variabel $(\mathrm{Y})$ yang digunakan adalah Jurusan Matematika.. Sedangkan untuk variabel $(X)$ yang digunakan dalam penelitian ini yaitu terdiri dari biaya kuliah $\left(X_{1}\right)$, akreditas Jurusan $\left(X_{2}\right)$, beasiswa $\left(X_{3}\right)$, dorongan orang tua $\left(X_{4}\right)$, dorongan teman $\left(X_{5}\right)$, minat dan bakat $\left(X_{6}\right)$, prospek lulusan $\left(X_{7}\right)$, dan lowongan kerja $\left(\mathrm{X}_{8}\right)$.

\subsection{Prosedur Pengolahan Data}

Prosedur pengolahan data pada penelitian ini adalah pengumpulan data, Uji Validitas dan Uji Reliabilitas, jika data tidak valid dan reliabel maka pertanyaan yang tidak valid dan reliabel dihilangkan dalam kuesioner, Jika sudah valid dan reliabel maka dapat dilanjudkan, Uji Chi Square, Analisis korespondensi, kesimpulan. 


\section{HASIL DAN PEMBAHASAN}

\subsection{Hasil Penelitian}

\subsubsection{Uji Validitas}

Pengujian validitas dilakukan pada setiap pertanyaan dengan menggunakan korelasi pearson product moment. Setiap pertanyaan dikatakan valid apabila $t_{\text {hitung }}>$ $t_{\text {tabel }}$ (Nurgiyantoro, dkk, 2004). Hasil uji tersebut terlihat bahwa semua pertanyaan adalah valid karena semua nilai $t_{\text {hitung }}$ lebih besar dari nilai $t_{\text {tabel }}$, dengan nilai $t_{\text {tabel }}=t_{\frac{1}{2} \alpha ; n-2}=t_{0,025 ; 218}=1,97$, dengan $\alpha=0,05$ dan derajat kebabasan $(\mathrm{dk}) n-2$ yaitu 248 .

\subsubsection{Uji Reliabilitas}

Uji reliabilitas hanya dilakukan pada pertanyaan yang valid. Metode yang digunakan untuk melakukan pengujian reliabilitas yaitu metode alpha cronbach $(\alpha)$. Apabila $\alpha<0,6$ maka pertanyaan tersebut dianggap tidak valid dan reliabel. Dari hasil uji reliabilitas diperoleh bahwa nilai alpha cronbach $(\alpha)$ yaitu 0,623 yang berarti pertanyaan dalam kuesioner tersebut adalah reliabel.

\subsection{Uji Chi Scuare}

Uji yang sesuai untuk mengetahui ada tidaknya hubungan antara dua variabel kategori yaitu hubungan / kedekatan anrara Jurusan Matematika di FMIPA UNTAD dan faktor alasan Mahasiswa dalam pemilihan Jurusan yang berupa tabel kontingensi adalah dengan pengujian uji chi scuare. Jika hipotesis nol diterima bila $\mathrm{X}^{2}<$ nilai kritis dan sebaliknya jika hipotesis nol ditolak bila $X^{2}>$ nilai kritis (Anggraini, 2011). Dari tabel terlihat bahwa variabel faktor minat dan bakat, faktor prospek lulusan serta faktor lowongan kerja hipotesis nolnya ditolak karena $X^{2}>9,488$ sehingga ada hubungan antara Jurusan Matematika di FMIPA UNTAD dan faktor alasan Mahasiswa dalam pemilihan Jurusan.

Tabel 1 : Uji chi scuare

\begin{tabular}{|c|c|c|}
\hline $\begin{array}{c}\text { Faktor Alasan Mahasiswa Dalam } \\
\text { Pemilihan Jurusan }\end{array}$ & $\begin{array}{c}\text { P-Value } \\
\left(\mathrm{X}^{2}\right)\end{array}$ & $\begin{array}{c}\text { Nilai Kritis } \\
\left(\mathrm{X}^{2} \alpha \mathrm{df}(\mathrm{B}-1)(\mathrm{k}-1)\right)\end{array}$ \\
\hline Biaya Kuliah & 8,106 & 9,488 \\
\hline Agreditas Jurusan & 6,085 & 9,488 \\
\hline Beasiswa & 5,750 & 9,488 \\
\hline Dorongan Otang Tua & 7,747 & 9,488 \\
\hline Dorongan Teman & 8,652 & 9,488 \\
\hline Minat dan Bakat & 11,161 & 9,488 \\
\hline Prospek Lulusan & 14,557 & 9,488 \\
\hline
\end{tabular}




\subsection{Analisis Korespondensi}

\subsubsection{Tabel Kontingensi}

Tabel kontingensi disusun berdasarkan hasil data pengamatan kuesioner dengan melibatkan dua variabel yaitu variabel baris dan variabel kolom (Mattjik AA \& Sumertajaya IM, 2011). Pada tabell kontingensi yang merupakan variabel baris yaitu Jurusan Matematika di FMIPA UNTAD dan variabel kolom merupakan faktor alasan Mahasiswa dalam pemilihan Jurusan yang dapat ditunjukan pada tabel sebagai berikut:

Tabel 2 : kontingensi faktor minat dan bakat

\section{Correspondence Table}

\begin{tabular}{|l|r|r|r|r|r|r|}
\hline \multirow{2}{*}{ Jurusan } & \multicolumn{2}{l|}{ Minat_dan_Bakat } \\
\cline { 2 - 8 } & STS & TS & KS & S & SS & Active Margin \\
\hline Matematika & 4 & 12 & 25 & 49 & 35 & 125 \\
Statistika & 4 & 7 & 20 & 34 & 60 & 125 \\
Active Margin & 8 & 19 & 45 & 83 & 95 & 250 \\
\hline
\end{tabular}

Tabel 3 : kontingensi faktor prospek lulusan

Correspondence Table

\begin{tabular}{|l|r|r|r|r|r|r|}
\hline \multirow{2}{*}{ Jurusan } & \multicolumn{2}{l|}{ Prospek_Lulusan } \\
\cline { 2 - 8 } & STS & \multicolumn{1}{l|}{ TS } & KS & S & SS & Active Margin \\
\hline Matematika & 3 & 9 & 30 & 47 & 36 & 125 \\
Statistika & 2 & 8 & 15 & 36 & 64 & 125 \\
Active Margin & 5 & 17 & 45 & 83 & 100 & 250 \\
\hline
\end{tabular}

Tabel 4 : kontingensi faktor lowongan kerja

Correspondence Table

\begin{tabular}{|l|r|r|r|r|r|r|}
\hline \multirow{2}{*}{ Jurusan } & \multicolumn{6}{l|}{ Lowongan_Kerja } \\
\cline { 2 - 8 } & STS & TS & KS & S & SS & Active Margin \\
\hline Matematika & 3 & 8 & 30 & 57 & 27 & 125 \\
Statistika & 1 & 5 & 25 & 42 & 52 & 125 \\
Active Margin & 4 & 13 & 55 & 99 & 79 & 250 \\
\hline
\end{tabular}


3.3.2. Pola Hubungan Antara Pemilihan Jurusan Dengan Minat dan Bakat

Tabel 5 : inersia dan proporsi varians untuk jurusan dengan minat dan bakat

\begin{tabular}{|l|c|c|c|c|c|}
\hline Dimensi & $\begin{array}{c}\text { Nilai } \\
\text { Singular }\end{array}$ & Nilai Eigen & $\begin{array}{c}\text { Chi- } \\
\text { Square }\end{array}$ & $\begin{array}{c}\text { Persen } \\
\text { Proporsi }\end{array}$ & $\begin{array}{c}\text { Persen } \\
\text { Kumulatif }\end{array}$ \\
\hline 1 & 21,1 & 4,5 & & 100,0 & 100,0 \\
\hline Total & 4,5 & 11,161 & 100,0 & 100,0 \\
\hline \multicolumn{5}{|l}{ Derajat Bebas 4 }
\end{tabular}

Tabel 5 merupakan inersia dan proporsi variabel pemilihan jurusan dengan minat dan bakat yang menghasilkan satu dimensi. Pada dimensi ini menerangakan nilai proporsi $100 \%$ keragaman data dengan nilai inersia (Nilai Eigen) sebesar 4,5\%. Sehingga total variasi yang bisa diterangkan pada dimensi satu adalah $100 \%$. Pada dimensi satu untuk kategori jurusan matematika dan statistika masing-masing memiliki nilai kontribusi sebesar 50,0\%. Kemudian untuk kategori minat dan bakat pada dimensi satu yang memiliki nilai kontribusi terbesar diberikan oleh minat dan bakat dengan kriteria sangat setuju (SS) sebesar 58,9\%, minat dan bakat dengan kriteria setuju (S) sebesar $24,3 \%$, minat dan bakat dengan kriteria tidak setuju (TS) sebesar $11,8 \%$, minat dan bakat dengan kriteria kurang setuju (KS) sebesar $0,5 \%$ sedangkan minat dan bakat dengan kriteria sangat tidak setuju (STS) tidak memiliki nilai kontribusi terlihat pada tabel 6 .

Tabel 6 : Nilai Kontribusi Untuk Pemilihan Jurusan Dengan Minat Dan Bakat

Overview Row Pointsa

\begin{tabular}{|c|c|c|c|c|c|c|}
\hline \multirow[t]{3}{*}{ Jurusan } & \multirow[t]{3}{*}{ Mass } & Score in & \multirow[t]{3}{*}{ Inertia } & \multicolumn{3}{|l|}{ Contribution } \\
\hline & & \multirow[t]{2}{*}{1} & & $\begin{array}{l}\text { Of Point to Inertia } \\
\text { of Dimension }\end{array}$ & \multicolumn{2}{|c|}{$\begin{array}{l}\text { Of Dimension to } \\
\text { Inertia of Point }\end{array}$} \\
\hline & & & & 1 & 1 & Total \\
\hline Matematika &, 500 &,- 460 & ,022 &, 500 & 1,000 & 1,000 \\
\hline Statistika &, 500 & ,460 & ,022 &, 500 & 1,000 & 1,000 \\
\hline Active Total & 1,000 & & ,045 & 1,000 & & \\
\hline
\end{tabular}




\section{a. Symmetrical normalization}

\section{Overview Column Pointsa}

\begin{tabular}{|c|c|c|c|c|c|c|}
\hline \multirow{3}{*}{$\begin{array}{l}\text { Minat_dan_Bak } \\
\text { at }\end{array}$} & \multirow[t]{3}{*}{ Mass } & \multirow{3}{*}{$\begin{array}{l}\text { Score in } \\
\text { Dimension } \\
1\end{array}$} & \multirow[t]{3}{*}{ Inertia } & \multicolumn{3}{|l|}{ Contribution } \\
\hline & & & & $\begin{array}{l}\text { Of Point to } \\
\text { Inertia of } \\
\text { Dimension }\end{array}$ & \multicolumn{2}{|c|}{$\begin{array}{l}\text { Of Dimension } \\
\text { to Inertia of } \\
\text { Point }\end{array}$} \\
\hline & & & & 1 & 1 & Total \\
\hline STS & ,032 &, 000 &, 000 &, 000 &, 000 & ,000 \\
\hline TS & ,076 &,- 572 & ,005 & ,118 & 1,000 & 1,000 \\
\hline KS & 180 &,- 242 &, 002 &, 050 & 1,000 & 1,000 \\
\hline$S$ & ,332 &,- 393 & ,011 & ,243 & 1,000 & 1,000 \\
\hline SS & ,380 &, 572 & ,026 &, 589 & 1,000 & 1,000 \\
\hline Active Total & 1,000 & &, 045 & 1,000 & & \\
\hline
\end{tabular}

a. Symmetrical normalization

\subsubsection{Pola Hubungan Antara Pemilihan Jurusan Dengan Prospek Lulusan}

Tabel 7 : inersia dan proporsi varians untuk jurusan dengan prospek lulusan

\begin{tabular}{|c|c|c|c|c|c|}
\hline Dimensi & $\begin{array}{c}\text { Nilai } \\
\text { Singular }\end{array}$ & Nilai Eigen & Chi-Square & $\begin{array}{c}\text { Persen } \\
\text { Proporsi }\end{array}$ & $\begin{array}{c}\text { Persen } \\
\text { Kumulatif }\end{array}$ \\
\hline 1 & 24,1 & 5,8 & & 100,0 & 100,0 \\
\hline Total & 5,8 & 14,557 & 100,0 & 100,0 \\
\hline \multicolumn{5}{|l}{ Derajat Bebas 4 }
\end{tabular}

Tabel 7 merupakan inersia dan proporsi variabel pemilihan jurusan dengan prospek lulusan yang menghasilkan satu dimensi. Pada dimensi ini menerangakan nilai proporsi $100 \%$ keragaman data dengan nilai inersia (Nilai Eigen) sebesar 5,8\%. Sehingga total variasi yang bisa diterangkan pada dimensi satu adalah $100 \%$. Pada dimensi satu untuk kategori jurusan matematika dan statistika masing-masing memiliki nilai kontribusi sebesar 50,0\%. Kemudian untuk kategori minat dan bakat pada dimensi satu yang memiliki nilai kontribusi terbesar diberikan oleh prospek lulusan 
dengan kriteria sangat setuju (SS) sebesar 53,9\%, prospek lulusan dengan kriteria kurang setuju (KS) sebesar $34,3 \%$, prospek lulusan dengan kriteria setuju (S) sebesar $10,0 \%$, prospek lulusan dengan kriteria sangat tidak setuju (STS) sebesar 1,4\% sedangkan prospek lulusan dengan kriteria tidak setuju (TS) hanya memiliki nilai kontribusi sebesar $0,4 \%$ terlihat pada tabel 8 .

Tabel 8 : Nilai Kontribusi Untuk Pemilihan Jurusan Dengan Prospek Lulusan

\section{Overview Row Points ${ }^{a}$}

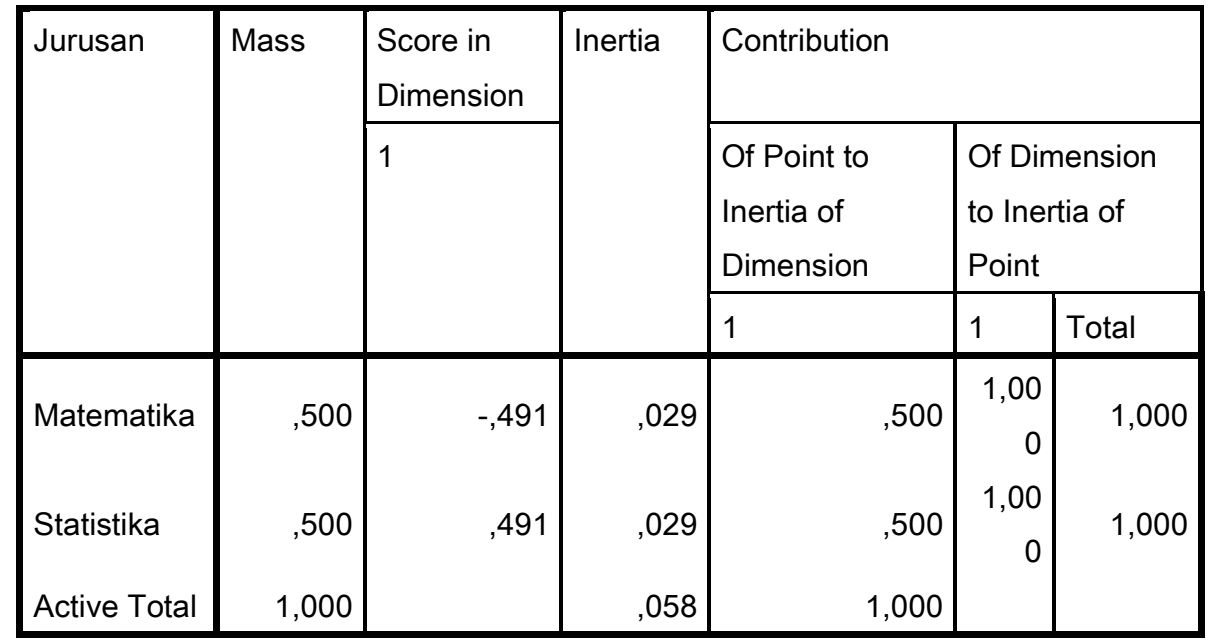

a. Symmetrical normalization

Overview Column Pointsa

\begin{tabular}{|c|c|c|c|c|c|c|}
\hline \multirow{3}{*}{$\begin{array}{l}\text { Prospek_Lulus } \\
\text { an }\end{array}$} & \multirow[t]{3}{*}{ Mass } & \multirow{3}{*}{$\begin{array}{l}\text { Score in } \\
\text { Dimension } \\
1\end{array}$} & \multirow[t]{3}{*}{ Inertia } & \multicolumn{3}{|l|}{ Contribution } \\
\hline & & & & $\begin{array}{l}\text { Of Point to } \\
\text { Inertia of } \\
\text { Dimension }\end{array}$ & \multicolumn{2}{|c|}{$\begin{array}{l}\text { Of Dimension } \\
\text { to Inertia of } \\
\text { Point }\end{array}$} \\
\hline & & & & 1 & 1 & Total \\
\hline STS & ,020 &,- 407 & 001 & 014 & 1,000 & 1,000 \\
\hline TS &, 068 &,- 120 & ,000 & ,004 & 1,000 & 1,000 \\
\hline KS & ,180 &,- 679 & 020 & ,343 & 1,000 & 1,000 \\
\hline$S$ & ,332 &,- 270 & ,006 & , 100 & 1,000 & 1,000 \\
\hline SS &, 400 &, 570 &, 031 &, 539 & 1,000 & 1,000 \\
\hline Active Total & 1,000 & & ,058 & 1,000 & & \\
\hline
\end{tabular}

a. Symmetrical normalization 
3.3.4. Pola Hubungan Antara Pemilihan Jurusan Dengan Lowongan Kerja

Tabel 9 : inersia dan proporsi varians untuk jurusan dengan lowongan kerja

\begin{tabular}{|c|c|c|c|c|c|}
\hline Dimensi & $\begin{array}{c}\text { Nilai } \\
\text { Singular }\end{array}$ & Nilai Eigen & Chi-Square & $\begin{array}{c}\text { Persen } \\
\text { Proporsi }\end{array}$ & $\begin{array}{c}\text { Persen } \\
\text { Kumulatif }\end{array}$ \\
\hline 1 & 22,2 & 4,9 & & 100,0 & 100,0 \\
\hline Total & 4,9 & 12,331 & 100,0 & 100,0 \\
\hline \multicolumn{5}{|l}{ Derajat Bebas 4 } \\
\hline
\end{tabular}

Tabe 9 merupakan inersia dan proporsi variabel pemilihan jurusan dengan lowongan kerja yang menghasilkan satu dimensi. Pada dimensi ini menerangakan nilai proporsi $100 \%$ keragaman data dengan nilai inersia (Nilai Eigen) sebesar 4,9\%. Sehingga total variasi yang bisa diterangkan pada dimensi satu adalah $100 \%$. Pada dimensi satu untuk kategori jurusan matematika dan statistika masing-masing memiliki nilai kontribusi sebesar 50,0\%. Kemudian untuk kategori lowongan kerja pada dimensi satu yang memiliki nilai kontribusi terbesar diberikan oleh lowongan kerja dengan kriteria sangat setuju (SS) sebesar 64,2\%, lowongan kerja dengan kriteria setuju (S) sebesar $18,4 \%$, lowongan kerja dengan kriteria sangat tidak setuju (STS) sebesar $8,1 \%$, lowongan kerja dengan kriteria tidak setuju (TS) sebesar $5,6 \%$ sedangkan lowongan kerja dengan kriteria kurang setuju (KS) hanya memiliki nilai kontribusi sebesar $3,7 \%$ terlihat pada tabel 10 .

Tabel 10 : Nilai Kontribusi Untuk Pemilihan Jurusan Dengan Lowongan Kerja Overview Row Pointsa

\begin{tabular}{|c|c|c|c|c|c|c|}
\hline \multirow[t]{3}{*}{ Jurusan } & \multirow[t]{3}{*}{ Mass } & \multirow{3}{*}{$\begin{array}{l}\text { Score in } \\
\text { Dimension } \\
1\end{array}$} & \multirow[t]{3}{*}{ Inertia } & \multicolumn{3}{|l|}{ Contribution } \\
\hline & & & & $\begin{array}{l}\text { Of Point to Inertia } \\
\text { of Dimension }\end{array}$ & \multicolumn{2}{|c|}{$\begin{array}{l}\text { Of Dimension } \\
\text { to Inertia of } \\
\text { Point }\end{array}$} \\
\hline & & & & 1 & 1 & Total \\
\hline Matematika &, 500 &,- 471 & ,025 &, 500 & 1,000 & 1,000 \\
\hline Statistika &, 500 & ,471 & ,025 &, 500 & 1,000 & 1,000 \\
\hline Active Total & 1,000 & & ,049 & 1,000 & & \\
\hline
\end{tabular}

a. Symmetrical normalization

\section{Overview Column Pointsa}




\begin{tabular}{|c|c|c|c|c|c|c|}
\hline \multirow{3}{*}{$\begin{array}{l}\text { Lowongan_Kerj } \\
\text { a }\end{array}$} & \multirow[t]{3}{*}{ Mass } & \multirow{3}{*}{$\begin{array}{l}\text { Score in } \\
\text { Dimension } \\
1\end{array}$} & \multirow[t]{3}{*}{ Inertia } & \multicolumn{3}{|l|}{ Contribution } \\
\hline & & & & $\begin{array}{l}\text { Of Point to } \\
\text { Inertia of } \\
\text { Dimension }\end{array}$ & \multicolumn{2}{|c|}{$\begin{array}{l}\text { Of Dimension to } \\
\text { Inertia of Point }\end{array}$} \\
\hline & & & & 1 & 1 & Total \\
\hline STS & ,016 & $-1,061$ & ,004 & ,081 & 1,000 & 1,000 \\
\hline TS & ,052 &,- 490 & ,003 & ,056 & 1,000 & 1,000 \\
\hline KS & ,220 &,- 193 & ,002 & ,037 & 1,000 & 1,000 \\
\hline$S$ & ,396 &,- 322 & ,009 & ,184 & 1,000 & 1,000 \\
\hline SS & ,316 & ,672 & ,032 & ,642 & 1,000 & 1,000 \\
\hline Active Total & 1,000 & & ,049 & 1,000 & & \\
\hline
\end{tabular}

a. Symmetrical normalization

\section{KESIMPULAN}

Berdasarkan hasil analisis data yang telah dilakukan, maka diperoleh kesimpulan sebagai berikut:

1. Dari hasil pengujian chi square diperoleh 3 variabel faktor yang masuk kedalam analisis korespondensi terdiri dari variabel faktor minat dan bakat, faktor prospek lulusan serta faktor lowongan kerja. Masing-masing variabel tersebut mempunyai nilai chi square $X^{2}>9,488$ yang berarti ada hubungan antara Jurusan Matematika di FMIPA UNTAD dan faktor alasan Mahasiswa dalam pemilihan Jurusan.

2. Pada hasil analisis korespondensi pola hubungan antara pemilihan jurusan dengan minat dan bakat, prospek lulusan serta lowongan kerja yaitu menghasilkan anatara lain :

- $\quad$ Pola hubungan antara pemilihan jurusan dengan minat dan bakat hanya menghasilkan 1 dimensi serta mempunyai nilai kontribusi terbesar pada kriteria sangat setuju (SS) yang bernilai $58,9 \%$.

- $\quad$ Pola hubungan antara pemilihan jurusan dengan prospek lulusan hanya menghasilkan 1 dimensi serta mempunyai nilai kontribusi terbesar pada kriteria sangat setuju (SS) yang bernilai $53,9 \%$.

- Pola hubungan antara pemilihan jurusan dengan lowongan kerja hanya menghasilkan 1 dimensi serta mempunyai nilai kontribusi terbesar pada kriteria sangat setuju (SS) yang bernilai $64,2 \%$.

Dari hasil analisis korespondensi melalui program SPSS tidak menghasilkan plot pola hubungan antara pemilihan jurusan dengan faktor alasan mahasiswa disebabkan kurangnya 
variabel jurusan yang diteliti, karena peneliti hanya meneliti jurusan matematika yang terdiri dari prodi matematika dan prodi statistika.

\section{DAFTAR PUSTAKA}

[1] Anggraini, 2011, Analisis Korespondensi Hubungaan Antara Kondisi Sekolah, Tenaga Pengajar dan Sarana Belajar Terhadap Prestasi Sekolah: Studi Kasus SMA \& SMK Jakarta Selatan 2010), Universitas Islam Negeri Syafir Hidayatullah, (Online), (http://repository.uinjkt.ac.id/dspace/bitstream/123456789/4825/1/Anggraini-FST.pdf) , diakses 18 September 2014.

[2] Chofifatul Jannah, 2011, Analisis Korespondensi Untuk Mengetahui Alasan Mahasiswa Memilih Jurusan di FMIPA Universitas Negeri Malang: Studi Kasus Mahasiswa Non Kependidikan FMIPA, Universitas Negeri Malang, (Online), (http://jurnalonline.um.ac.id/data/artikel/artikel91D0DA94E54E018161D00749F1E0D7 9D.pdf, diakses 18 September 2014.

[3] Dessler, 1984, Manajemen Personal : Teknik dan Konsep Modern, Ahli Bahasa oleh Agus Dharma (Edisi Ketiga), Jakarta : Erlangga.

[4] Mattjik, A.A., \& Sumertajaya, I.M., 2011, Sidik Peubah Ganda Dengan Menggunakan SAS, Diterbitkan Oleh IPB Press, IPB Darmaga, Bogor.

[5] Nurgiyantoro, dkk., 2004, Statistik Terapan Untuk Penelitian IImu-ilmu Sosial, Gajah Mada University Press, Yogyakarta. 